\title{
First-Eutectic Features of Polar Metals in Double Systems
}

\author{
Alexander L. Shimkevich, Inessa Yu. Shimkevich \\ NRC Kurchatov Institute, Moscow, Russia \\ Email shimkevich_al@nrcki.ru
}

How to cite this paper: Shimkevich, A.L. and Shimkevich, I.Y. (2017) First-Eutectic Features of Polar Metals in Double Systems. Journal of Crystallization Process and Technology, 7, 55-63. https://doi.org/10.4236/jcpt.2017.73004

Received: May 31, 2017

Accepted: July 3, 2017

Published: July 6, 2017

Copyright $\odot 2017$ by authors and Scientific Research Publishing Inc. This work is licensed under the Creative Commons Attribution International License (CC BY 4.0).

http://creativecommons.org/licenses/by/4.0/ (c) (i) Open Access

\begin{abstract}
It is known that the dense part of any liquid metal consists of ramified clusters of almost regular tetrahedrons (triangular pyramids with atoms in their vertexes) that are connected into chains by faces. Any metal additive as a second component of liquid alloy can be both beyond these clusters as separated atoms and into them as inherent clusters. The liquid-metal alloy transfers into the second state, at the first eutectic of the solvent. This polymorphic transition of liquid matrix is discovered in the systems, $\mathrm{Pb}-\mathrm{K}$ and $\mathrm{Na}-\mathrm{Pb}$, by molecular-dynamic simulating their microstructure and in experiments on scattering slow neutrons by these alloys of different compositions. In the first system, the obtained results identify both the homogeneous alloy at low concentrations of potassium in liquid lead and the alloy clustering, $\left(\mathrm{Pb}_{4} \mathrm{~K}\right)_{n}$, at potassium concentrations following the eutectic, $\mathrm{Pb}_{0.91} \mathrm{~K}_{0.09}$. In the second one at the concentrations of lead more than $2 \%$, just the second state is discovered with the clusters, $\left(\mathrm{Na}_{4} \mathrm{~Pb}\right)_{n}$. One can expect the same polymorphic transition in the eutectic, $\mathrm{Na}_{0.93} \mathrm{Tl}_{0.07}$, with the micro-inhomogeneity, $\left(\mathrm{Na}_{6} \mathrm{Tl}\right)_{n}$, and with the melting point of $64 \mathrm{C}$. This eutectic maintained by the oxygen-free technology and enriched by the isotope, ${ }^{205} \mathrm{Tl}$, can become the best coolant for fast nuclear reactors due to the depressed chemical activity of sodium and composition stability.
\end{abstract}

\section{Keywords}

Tetrahedral Cluster, Liquid-Metal Eutectic, Lead and Potassium, Sodium and Thallium, Polymorphic Transition

\section{Introduction}

The liquid alkali metals and heavy metals are always characterized by existence of chemical compound clusters in their alloys [1] [2]. For example, the clusters, $\left(\mathrm{Na}_{4} \mathrm{~Pb}\right)_{n}$ and $(\mathrm{NaPb})_{m}$, are being formed in liquid sodium by lead at 20 and 50 
mol\% respectively [2]. The first cluster is caused by the chemical compound, $\mathrm{Na}_{15} \mathrm{~Pb}_{4}$, which manages the liquid-alloy microstructure on the sodium side of the phase diagram due to the strong polarity of these metals: sodium is the electropositive element and lead is the electronegative one. Therefore, the first gives away electron $\left(\mathrm{Na}^{+}\right)$while the second accepts it $\left(\mathrm{Pb}^{-}\right)$and serves as an oxidizer in liquid sodium.

If unifying their contrasts in the alloy after the first eutectic, we will obtain the liquid-metal coolant with components that fulfill differing technological functions: sodium provides the low corrosion activity of the eutectic and lead in the colloidal form inhibits the chemical activity of sodium right up to automatic shut-down its fire outdoors [3] [4].

Such polymorphic model seems most realistic for the liquid sodium alloy with any heavy metal [5] [6] [7] [8]. However some aspects of forming the colloidal alloy remain not quite understood and they require the analysis of phase diagrams in the neighborhood of the first eutectic of solvent. This knowledge can be useful for choosing the optimal eutectic modification of the sodium coolant for the fast nuclear reactors.

In this connection, it is reasonable to choose for sodium a polar additive which has the first eutectic in the concentration range of $1 \%-10 \%$, for example, $\mathrm{Na}_{0.93} \mathrm{Tl}_{0.07}$, [9] with melting point of $64 \mathrm{C}$. Such liquid alloy enriched by the isotope, ${ }^{205} \mathrm{Tl}$, can become attractive modification of sodium coolant maintained by oxygen-free technology for depressing its chemical activity. We will argue this choice in this paper.

On the other hand, one can verify the model of clustering the second component in the first eutectic of the basic component (solvent) by such analysis.

\section{Polymorphic Transition of Liquid Alloy}

The molecular-dynamic (MD) simulation shows that clustering the ions $\left(\mathrm{Na}^{+}\right.$, $\mathrm{Pb}^{-}$) in the alloy, $\mathrm{Na}-\mathrm{Pb}$, form the ramified percolation chain which is quickly being transformed in separate clusters [6] [8] [10]. At the same time, frequent (by period of $\leq 3 \mathrm{ps}$ ) recharging sodium particles $\left(\mathrm{Na} \leftrightarrow \mathrm{Na}^{+}\right)$only quickens the lead clustering (see Figure 1) but not changes the composition of these clusters, $\left(\mathrm{Na}_{2} \mathrm{~Pb}\right)_{n}$ in liquid sodium corresponding to the chemical compound, $\mathrm{Na}_{15} \mathrm{~Pb}_{4}$.

These clusters are characterized by strong molecular bonds between the ions, $\mathrm{Na}^{+}$and $\mathrm{Pb}^{-}$, and by a quick decay of their oscillations that is caused by the exchange of sodium atoms between clusters and the liquid matrix.

Thus, one can prove the impurity clustering and explain the strong changes of the microstructure of liquid sodium by little lead additives using the bipolar model, $\mathrm{Na}+\mathrm{Na}^{+}+\mathrm{Pb}^{-}$, in $\mathrm{MD}$ simulation of $\mathrm{Na}_{0.98} \mathrm{~Pb}_{0.02}$ liquid system with periodic recharging the nearest neighbors of solvent $\left(\mathrm{Na} \leftrightarrow \mathrm{Na}^{+}\right)$. It turned out that the typical time of the colloidal formation in this alloy does not exceed $50 \mathrm{ps}$ [10].

In contrast to $\mathrm{Na}-\mathrm{Pb}$ system, the liquid alloy of $\mathrm{Pb}-\mathrm{K}$ does not contain such clusters, $\left(\mathrm{Pb}_{4} \mathrm{~K}\right)_{n}$, when potassium concentration is less than 9\% [5] [6]. In this 


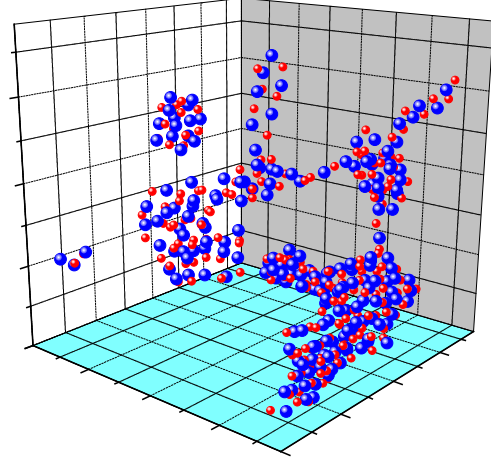

(a)

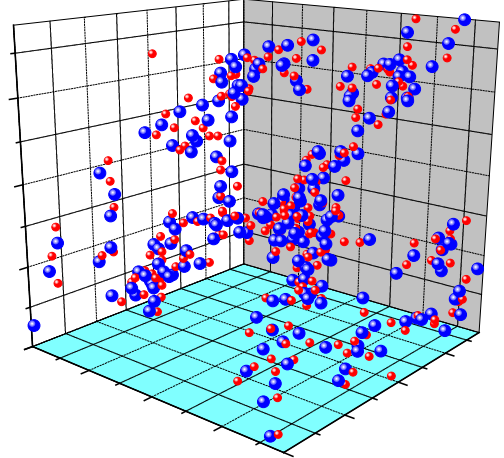

(b)

Figure 1. The ionic configurations in the MD cell on $9625 \mathrm{Na}$ atoms (are not shown), 201 $\mathrm{Na}^{+}$(red balls), and $201 \mathrm{~Pb}^{-}$(blue balls) in 100 ps after beginning the MD simulation without recharging sodium particles (a) and with this recharging (b); data are taken out of [10].

case, potassium ions are situated on the external faces of tetrahedrons in ramified tetrahedral chains of the lead dense part [5] [6] [11]. This liquid alloy has been named an introduction solution [7] as opposed to the addition one when the alloy contain clusters, $\left(\mathrm{Pb}_{4} \mathrm{~K}\right)_{n}$ at the potassium concentration is more than 9\%. The addition solution is the result of the first-order component phase transition [12] that is being demonstrated by the forepeak on the radial distribution function of atoms found in the neutron-diffraction experiments and by the MD simulation [5].

The dual character of topological position of the second component in the liquid basic component is caused by density fluctuations of the last. At the low concentration, impurity atoms cannot affect these fluctuations and cannot change the microstructure of dense liquid part, i.e., they are being introduced into the liquid (the introduction solution). At the increased concentration, the impurity atoms become the inherent elements of liquid dense part for forming proper clusters and the solution becomes colloidal (biphasic) for the second and homogeneous for the basic one (solvent) due to the quick exchange of its atoms between colloids and liquid matrix, i.e., they form the addition solution for the second component [7].

Such solution in the liquid metal system, $\mathrm{A}_{1-x} \mathrm{~B}_{x}$ is arising in the first eutectic, $x_{e l}$, of the solvent, A. Indeed, the liquidus line, $T_{l}(x)$, on the branch $\left(0 \leq x \leq x_{e 1}\right)$ of this eutectic is related to the introduction solution where the thermodynamic activity, $a_{1}$, of the solvent is being defined by the equation [7]

$$
a_{1}=\gamma_{\mathrm{A}}(1-2 x) /(1-x)
$$

where $\gamma_{\mathrm{A}}=\gamma_{1} \exp \left(-\Delta_{\mathrm{A}} / T\right)$ is the activity coefficient of the solvent in the non-ideal introduction solution. Then, the equation for $T_{l}(x)$ on its branch $\left(0 \leq x \leq x_{e 1}\right)$ is being found from Equation (1) for $a_{1}=1$ :

$$
T_{l}(x)=T_{m \mathrm{~A}} \ln \gamma_{1} / \ln \left[\gamma_{1}(1-2 x) /(1-x)\right] \text {. }
$$

Such the approach allows also to have found the liquidus line, $T_{l}(x)$, on the 
opposite branch $\left(x_{e 1} \leq x \leq x_{c}\right)$ of this eutectic related to the chemical compound, $\mathrm{A}_{k} \mathrm{~B}$, using the thermodynamic activity, $a_{2}$, of metal additive, $\mathrm{B}$, in the addition solution [7]:

$$
a_{2}=\gamma_{\mathrm{B}}[k x /(1+(k-1) x)]^{k}[x /(1-2 x)]^{1 / k n}
$$

where $\gamma_{\mathrm{B}}=\gamma_{2} \exp \left(-\Delta_{\mathrm{A}_{k} \mathrm{~B}} / T\right)$ is the activity coefficient of impurity, $\mathrm{B}$, in the non-ideal addition solution. Then, $T_{l}(x)$ on the branch $\left(x_{e 1} \leq x \leq x_{c}\right)$ is being found from Equation (3) for $a_{2}=1$ :

$$
T_{l}(x)=T_{m c} \frac{\ln \left[\gamma_{2} C\left(x_{c}\right) k x_{c} /\left(1+(k-1) x_{c}\right)\right]}{\ln \left[\gamma_{2} C(x) k x /(1+(k-1) x)\right]}
$$

where $x_{c} \approx 1 /(1+k)$ for the first chemical compound, $\mathrm{A}_{k} \mathrm{~B}$, and $C(x)=[x /(1-2 x)]^{1 / k^{2} n}$ is the amendment of clusters, $\left(\mathrm{A}_{k} \mathrm{~B}\right)_{n}$, to the liquid us line of the addition solution.

Obviously, the intersection of lines of Equations ((2) and (4)) defines the eutectic coordinate, $x_{e l}$, which characterizes the polymorphous transition of the liquid metal alloy [6]. In this transition point, the correlation radii, $R_{1}$ and $R_{2}$ (in relative units) that define representative regions of density and compound fluctuations respectively [13] differ sharply as a function of $x$ shown in Figure 2 .

One can see that sharply falling in the eutectic point $R_{2}$ specifies the decay of compound fluctuations in clusters of the chemical compound, $\mathrm{A}_{k} \mathrm{~B}$, against the density fluctuations of long waves in liquid alloy. The monotonous increase of $R_{2}$ in the some interval of $\mathrm{B}$ concentration should be interpreted as a region of cluster existence up to the precipitation of $\mathrm{A}_{k} \mathrm{~B}$ from the addition solution when $R_{2}$ increases sharply. The observed clustering of the component, $\mathrm{B}$, in the addition solution is the first-order phase transition in micro regions of liquid which has homogeneous character for the solvent, $\mathrm{A}$, and is characterized by the

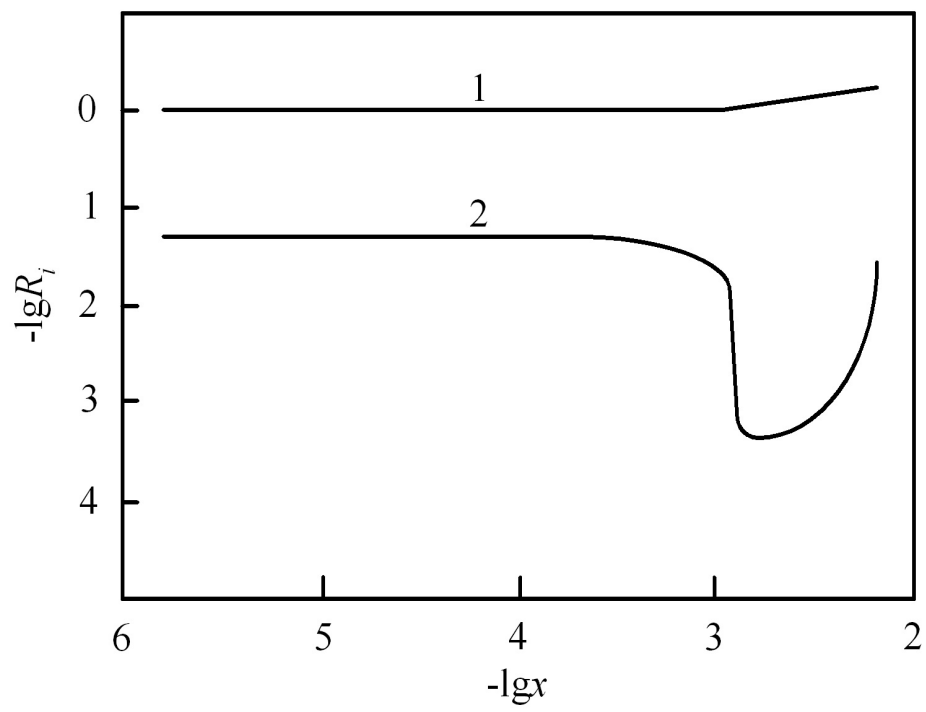

Figure 2. The logarithm of correlation radius, $R_{p}$ (in relative units) of density fluctuations (1) and compound fluctuations (2) as a function of B concentration, $x$, in the liquid-metal alloy, $\mathrm{A}_{1-x} \mathrm{~B}_{x}$, which has the first chemical compound, $\mathrm{A}_{k} \mathrm{~B}$; data are taken out of [13]. 
eutectic break of liquidus line as a change of the $B$ form in the alloy, $A_{1-x} B_{x}$ [13].

\section{Non-Homogeneity of Liquid-Metal Eutectics}

The contrasting properties of density and compound fluctuations (see Figure 2) are caused by the charge polarity of the alloy components: if one of them is electropositive, the other must be electronegative [4] [7]. Then, the first gives up an electron to the second for forming the colloidal particles, $\left(\mathrm{A}_{k} \mathrm{~B}\right)_{n}$, of the chemical compound, $\mathrm{A}_{k} \mathrm{~B}$, in the liquid-metal alloy. They can so change the properties that the first alloy eutectic will become an attractive liquid-metal coolant because its components fulfill differing technological functions: one of them can reduce the corrosion activity of the eutectic alloy and the other can inhibit its chemical activity. In addition, the boiling temperature of the alloy can be increased by the addition of high-boiling metal, for example, lead in liquid sodium [3]. The phase diagram of this system is shown in Figure 3 where the red dotted line is obtained using the equation (4) at the obtained activity coefficient of lead, $\gamma_{2} \sim 4 \times$ $10^{-3}$, for clusters $\left(\mathrm{Na}_{4} \mathrm{~Pb}\right)_{3}$.

Thus, the model of lead addition solution in liquid sodium good describes the liquidus line on the sodium side of the phase diagram of the system, $\mathrm{Pb}-\mathrm{Na}$. Here, $\gamma_{2} \sim 4 \times 10^{-3}$ indicates to strong bond of sodium and lead atoms in this solution by forming clusters, $\left(\mathrm{Na}_{4} \mathrm{~Pb}\right)_{3}$. From the value of $\gamma_{2}$, one can estimate a possible increase of the eutectic boiling point, $\Delta T_{b}$, by equation

$$
\Delta T_{b}=\left(R T_{b}^{2} / k \Delta H_{e}\right) \ln \gamma_{2}
$$

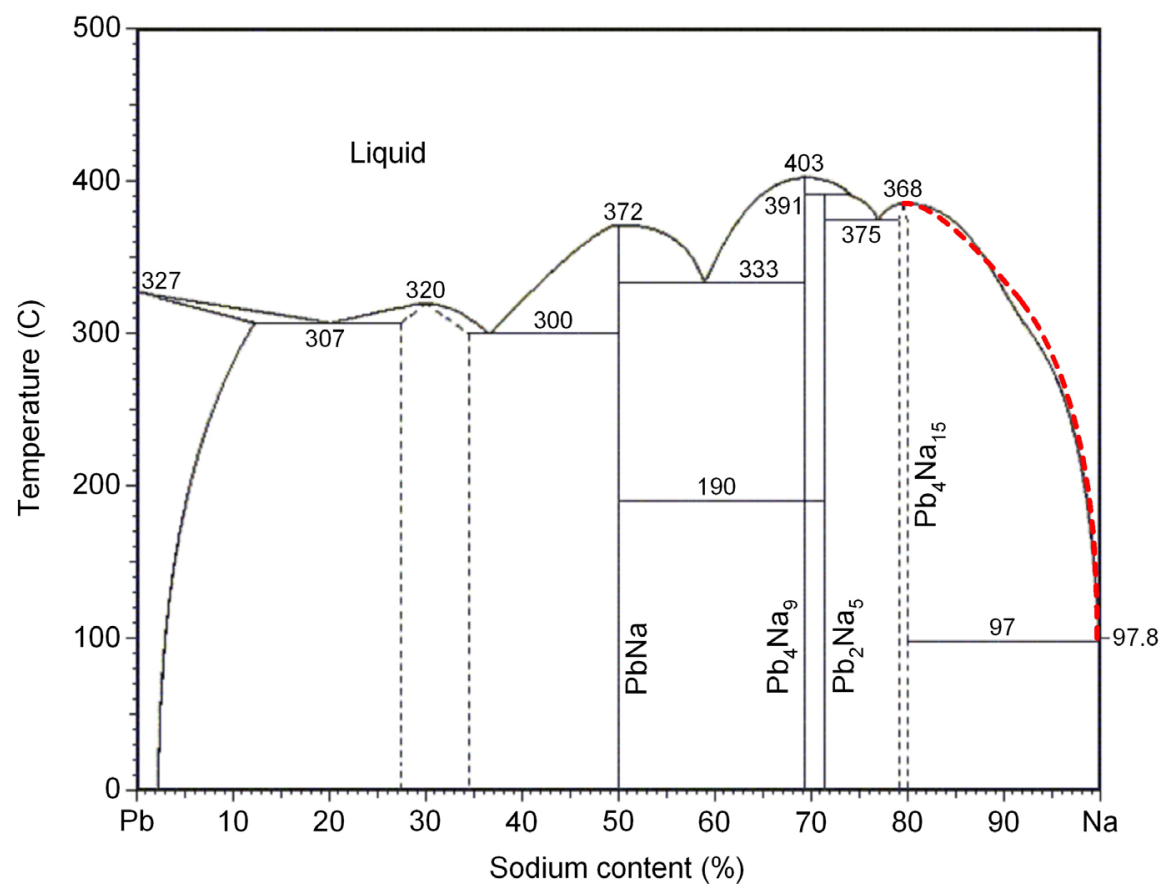

Figure 3. The phase diagram for double system, $\mathrm{Na}_{1-x} \mathrm{~Pb}_{x}$ [14]; the red dotted curve of liquidus is obtained by (4) when $\gamma_{2} \sim 4 \times 10^{-3}$ for the addition solution of lead in liquid sodium; one can see that this curve is in the good agreement with the experimental data $[14]$. 
that can amount to $150 \mathrm{~K}$ for the boiling point $T_{b}$ of sodium equal to $1156 \mathrm{~K}$, the heat of its evaporation, $\Delta H_{e}$ equal to $97.42 \mathrm{~kJ} / \mathrm{mol}$, and $R=8.31 \mathrm{~J} / \mathrm{mol} \cdot \mathrm{K}$ as the gas constant [15].

In the $\mathrm{Pb}_{1-x} \mathrm{~K}_{x}$ system, the model (1) - (4) identifies both the homogeneous introduction solution at low concentrations of potassium in liquid lead and the clusters, $\left(\mathrm{Pb}_{4} \mathrm{~K}\right)_{3}$, in the addition solution at potassium concentrations following the eutectic, $\mathrm{Pb}_{0.91} \mathrm{~K}_{0.09}$. The phase diagram of this system is shown in Figure 4 where the red dotted lines for liquidus near the first eutectic are obtained by Equations ((2) and (4)) at $\gamma_{2} \sim 2 \times 10^{-4}$.

Thus, the first eutectic of any liquid metal can essentially change its physical and chemical properties by forming inhomogeneous solution of polar additive in the liquid-metal alloy. Therefore using a metal additive of other polarity, one can modify a pure liquid-metal coolant for more effective operation in fast nuclear reactors.

\section{Modification of Sodium Coolant}

As seen in Figure 5, the double system, $\mathrm{Na}_{1-x} \mathrm{Tl}_{x}$, has the first eutectic at $x_{\mathrm{el}}=$ 0.071 [9]. Therefore, one can expect the same polymorphic transition of liquid alloy in this eutectic by forming the micro-inhomogeneity, $\left(\mathrm{Na}_{6} \mathrm{Tl}\right)_{n}$, at the melting point of $337 \mathrm{~K}$. This concept is checked by calculating the liquidus of this system (red dotted lines in Figure 5) near the eutectic, $\mathrm{Na}_{0.93} \mathrm{Tl}_{0.07}$, obtained by Equations ((2) and (4)) at $\gamma_{2} \sim 2 \times 10^{-5}$.

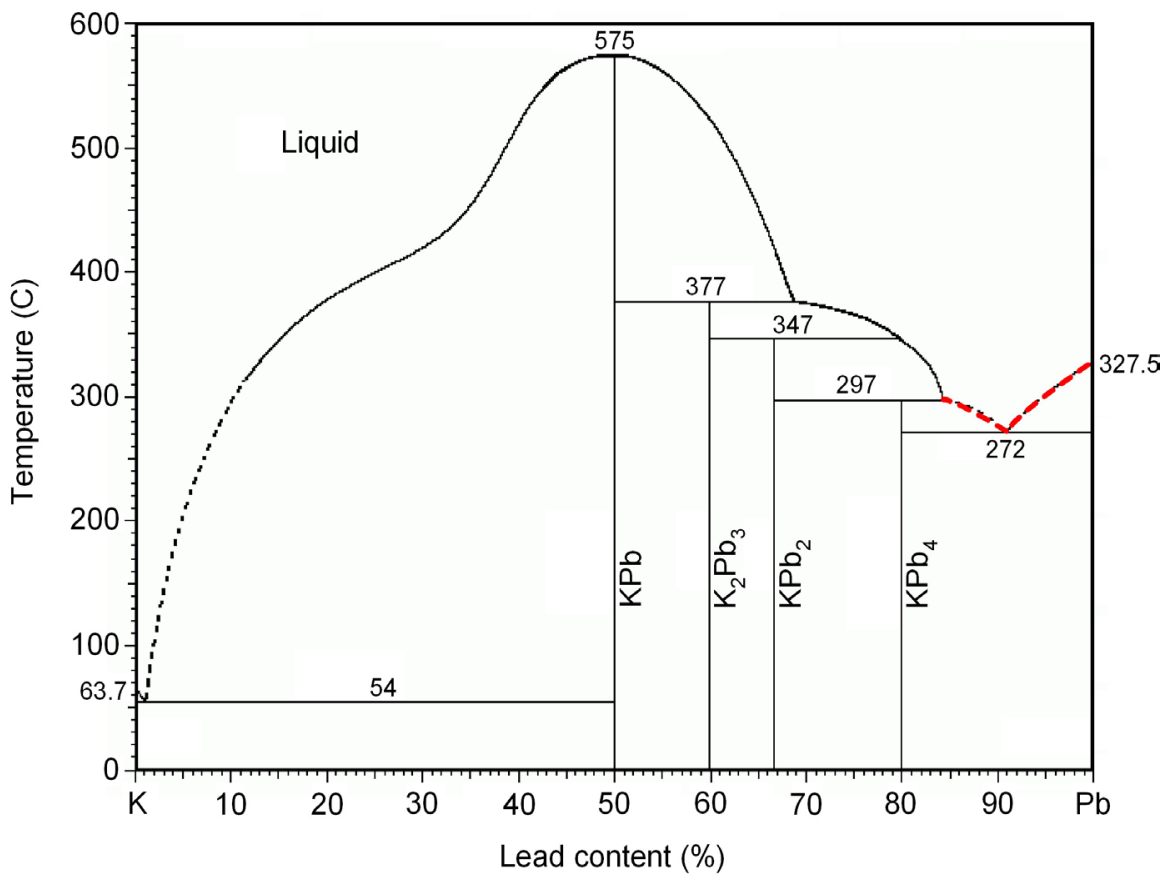

Figure 4. The phase diagram for double system, $\mathrm{Pb}_{1-x} \mathrm{~K}_{x}$ [16]; the right red dotted curve of liquidus is obtained by (2) for the introduction solution of potassium in liquid lead and the left curve is calculated by (4) when $\gamma_{2} \sim 2 \times 10^{-4}$ for the addition solution of potassium near the first eutectic $\left(x_{\mathrm{e} 1}=0.091\right)$; this calculation is in agreement with the experimental data [16]. 


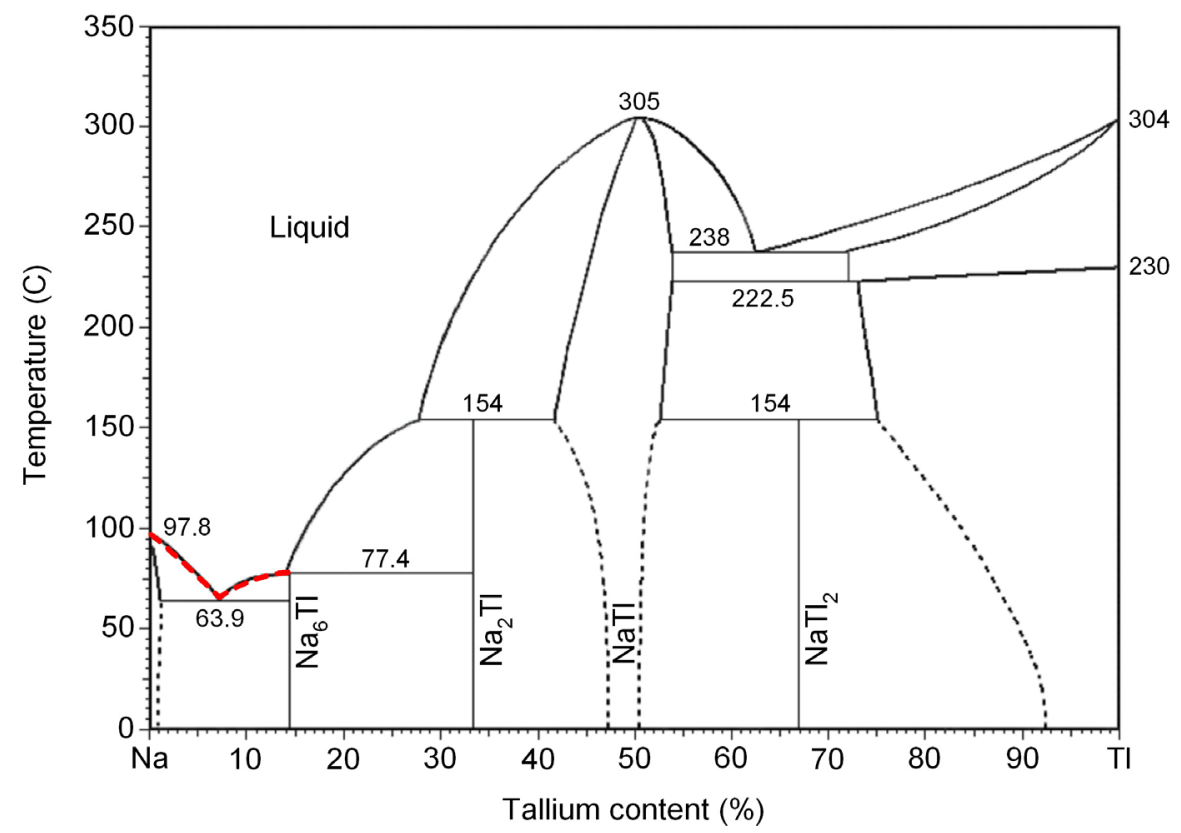

Figure 5. The phase diagram for double system, $\mathrm{Na}_{1-x} \mathrm{Tl}_{x}$ [9]; the left red dotted curve of liquidus is obtained by (2) for the introduction solution of thallium in liquid sodium and the right curve is calculated by (4) when $\gamma_{2} \sim 2 \times 10^{-5}$ for the addition solution of thallium near the first eutectic $\left(x_{\mathrm{e} 1}=0.071\right)$; this calculation is in accord with the experimental data [9].

Using (5) for this very small value of $\gamma_{2}$, one can estimate the increase of the eutectic boiling point, $T_{b}$, up to $1350 \mathrm{~K}$. Then, this eutectic maintained by the oxygen-free technology and enriched by the isotope, ${ }^{205} \mathrm{Tl}$, can become the best high-boiling coolant for the fast nuclear reactors having low chemical activity [4] [17].

\section{Conclusions}

It turned out that one can describe the liquidus near the first eutectic of the solvent in double systems of polar liquid metals as a solidification of two solutions (introduction and addition) on both branches of this eutectic respectively. The introduction solution is homogeneous and impurity atoms turn out introduced into the liquid matrix of the solvent.

In the eutectic and after, these atoms become the inherent elements of the liquid dense part and the alloy becomes colloidal (biphasic) for the impurity and homogeneous for the solvent due to a quick exchange of its atoms between colloids and the liquid matrix of the addition solution.

This concept is in the good agreement with the experimental data for double systems: $\mathrm{Na}_{1-x} \mathrm{~Pb}_{x}, \mathrm{~Pb}_{1-x} \mathrm{~K}_{x}, \mathrm{Na}_{1-x} \mathrm{Tl}_{x}$, near their first eutectics of the solvent.

It is shown that the first eutectic of the basic component changes essentially the physical and chemical properties of the alloy by forming colloidal solution of the second component which can increase the boiling point of the solvent, for example in $\mathrm{Na}_{0.93} \mathrm{Tl}_{0.07}$, on more than $150 \mathrm{~K}$.

It can become a good way for improving the up-to-date sodium and lead coo- 
lants of the fast nuclear reactors, for example, modifying them by eutectics: $\mathrm{Na}_{0.93} \mathrm{Tl}_{0.07}$ for the first and $\mathrm{Pb}_{0.83} \mathrm{Mg}_{0.17}$ for the second.

\section{Acknowledgements}

Authors thank their colleagues for active discussing the all aspects of eutectic modification of liquid-metal coolants of the fast nuclear reactors.

\section{References}

[1] Van der Lugt, W. (1991) Zintl Ions as Structural Units in Liquid Alloys. Physica Scripta, 39, 372. https://doi.org/10.1088/0031-8949/1991/T39/059

[2] Reijers, H.T.J. and van der Lugt, W. (1990) Molecular-Dynamics Study of Liquid $\mathrm{NaPb}, \mathrm{KPb}, \mathrm{RbPb}$, and CsPb Alloys. Physical Review B, 42, 3395-3405. https://doi.org/10.1103/PhysRevB.42.3395

[3] Subbotin, V.I., Arnoldov, M.N., Kozlov, F.A. and Shimkevich, A.L. (2002) LiquidMetal Coolants for Nuclear Power. Atomic Energy, 92, 29-40. https://doi.org/10.1023/A:1015050512710

[4] Alekseev, P.N. and Shimkevich, A.L. (2016) Efficacy of Eutectic Modification of Liquid-Metal Coolants. Atomic Energy, 119, 218-219. https://doi.org/10.1007/s10512-015-0050-2

[5] Blagoveshchenskii, N.M., Morozov, V.A., Novikov, A.G., Savostin, V.V., Shimkevich, A.L and Shimkevich, I.Y. (2005) Microscopic Structure of Liquid Lead-Potassium Alloys: Neutron-Diffraction and Molecular Dynamics Investigation. Physica B: Condensed Matter, 364, 255-262. https://doi.org/10.1016/j.physb.2005.04.021

[6] Kolokol, A.S., Shimkevich, A.L. and Shimkevich, I.Y. (2008) On Composition Converting Liquid Metal Alloys. Journal of Physics. Conference Series, 98, Article ID: 042021.

[7] Shimkevich, A.L. (2008) The Composition Principles for Designing Nuclear-Reactor Materials. N.N. PonomarevStepnoi Edition, IzdAt, Moscow. (In Russ)

[8] Shimkevich, I.Y. and Shimkevich, A.L. (2014) MD Simulated Microstructure of Liquid Sodium Alloyed with Lead. Materials Sciences and Applications, 5, 556-567. https://doi.org/10.4236/msa.2014.58058

[9] Grube, G. and Schmidt, A. (1936) The Na-Tl Phase Diagram. Zeitschrift für Elektrochemie, 42, 201-209.

[10] Shimkevich, A.L. and Shimkevich, I.Y. (2011) Molecular Dynamics Simulation of the Clustering of Minor Lead Additives in Liquid Sodium. Journal of Metallurgy, 2011, Article ID: 890321. https://doi.org/10.1155/2011/890321

[11] Kolokol, A.S. and Shimkevich, A.L. (2010) Topological Structure of Density Fluctuations in Condensed Matter. Journal of Non-Crystalline Solids, 356, 220-223.

[12] Ivanovsky, M.N., Morozov, V.A., Ponomarev-Stepnoi, N.N. and Shimkevich, A.L. (1988) Component First-Order Phase Transition. Soviet Atomic Energy, 65, 878881. https://doi.org/10.1007/bf01121245

[13] Shimkevich, A.L. (1999) The Fluctuation Theory of Impurity Micro-Heterogeneity of Liquid-Metal Coolants. Proceedings of the High School. Nuclear Power, No. 3, 616.

[14] Lamprecht, G.J., Dicks, L. and Crowther, P. (1968) Solubility of Metals in Liquid Sodium. II. The System Sodium-Lead. The Journal of Physical Chemistry, 72, 14391441. https://doi.org/10.1021/j100851a006

[15] Kikoin, I.K., Ed. (1976) Tables of Physical Constants. Atomizdat, Moscow. 
[16] Meijer, J.A., Geertsma, W. and Van der Lugt, W. (1985) Electrical Resistivities of Liquid Alkali-Lead and Alkali-Indium Alloys. Journal of Physics F: Metal Physics, 15, 899-910. http://iopscience.iop.org/0305-4608/15/4/014 https://doi.org/10.1088/0305-4608/15/4/014

[17] Alekseev, P.N., Shimkevich, A.L. and Shimkevich, I.Y. (2015) Eutectic Na-Tl and $\mathrm{Pb}-\mathrm{Mg}$ Alloys as Liquid-Metal Coolants for Fast Nuclear Reactors. In: Brebbia, C., Ed., Computational Methods and Experimental Measurements XVII, WIT Press, Southampton, 343-353. https://doi.org/10.2495/cmem150311

Submit or recommend next manuscript to SCIRP and we will provide best service for you:

Accepting pre-submission inquiries through Email, Facebook, LinkedIn, Twitter, etc. A wide selection of journals (inclusive of 9 subjects, more than 200 journals)

Providing 24-hour high-quality service

User-friendly online submission system

Fair and swift peer-review system

Efficient typesetting and proofreading procedure

Display of the result of downloads and visits, as well as the number of cited articles Maximum dissemination of your research work

Submit your manuscript at: http://papersubmission.scirp.org/

Or contact jcpt@scirp.org 